\title{
Analysis of Computer Skills and Happiness Levels of Electrical Engineering Students during Pandemic
}

\author{
Qurban A. Memon
}

\section{ABSTRACT}

\begin{abstract}
Since March 2019, UAE university has responded to challenges raised by the pandemic by transforming normal instruction platforms and assessments to online. The pandemic itself and online learning have affected students' skill level, job outlook and perception of the future. Engineering education, in particular, involves laboratory experience, field internships, industrial visits in addition to classroom learning. This study undertakes to analyze electrical engineering students' concerns raised by challenges due to pandemics. The study develops a hypothesis and validates it using data collected from electrical engineering students (of years 2,3 and 4) registered in the spring term of computer courses of electrical engineering. The data thus, collected is analyzed and suggests that electrical engineering students' happiness levels are low, the job outlook is weak, and skill development concerns are high due to virtual laboratory experience and absence of physical industrial visits/internships. Some recommendations are developed and presented.
\end{abstract}

Keywords: Electrical engineering, Engineering education, Engineering skills, Online learning, Pandemic, Virtual laboratory environment.
Published Online: September 21, 2021

ISSN: $2736-4534$

DOI: $10.24018 /$ ejedu.2021.2.5.167

Q. A. Memon*

EE Department, College of Engineering,

UAE University, United Arab Emirates

(e-mail: qurban.memon@uaeu.ac.ae)

*Corresponding Author

\section{INTRODUCTION}

The COVID-19 pandemic spread very quickly in the Middle East from February 2020. It was a normal face-toface learning mode until the UAE government reported some active cases of COVID-19 in early March 2020. To control the spread of COVID-19, the Ministry of Education (MoE) took quick action and closed educational institutions for two weeks. Instructions from federal governments restricted the movements of students and thus schools and universities continued to shut down from normal operations. With the new academic year 2020-2021, most of the students went online. The universities started using digital platforms like Zoom, Blackboard, Teams amongst others to support learning.

Over a year, a ravaging impact of the pandemic has been seen in the UAE and across the globe, and its impact on education has been intensive as the sudden change in learning mode to online did not come without its effects. The immediate challenges faced to learning were uneven access and affordability as online learning was individualized and interactive. However, the UAE government managed this quickly as several initiatives were launched in the direction of affordable, accessible, and available ICT infrastructure with support to digital services for online learning. The challenges this pandemic brought to parents, students, schools, and universities are numerous. Early research indicated that students are unequally affected, and so are the educational institutions. The restricted international travel, social isolation, worries about COVID-19, feeling of being at risk of financial losses have added another dimension to physical and mental health.

More research needs to be done to find information about COVID-19 induced challenges that have affected students, teachers, parents as well as institutional administrators so that evidence-based support programs may be developed to help facilitate affected groups. Tools of research that span all affected groups need to be applied to extract useful and potential data of concern. In literature, two popular ways to find related information about these challenges are: (i) surveys based on a questionnaire, and (ii) supplementary interviews. These tools need to be applied to people based on demography:

- for the effectiveness of the learning environment seen by students;

- how parents view it on part of learning satisfaction;

- for determining challenging issues faced by administrators in providing a learning environment and relevant assessment concerns;

- for the viability of learning framework on part of instructors;

- address other issues such as social isolation and lack of physical connectivity with peers and instructors.

This research report is divided into sections. In the next section, the literature review is presented that highlights how this pandemic has affected different groups of people in UAE institutions, especially engineering education. After that, the methodology is discussed where we intend to identify 
various tools, their description, and the way of using them to find related information from various targeted groups. The objective is to build ways of collecting data and analyze them to enable expanded services to affected groups. After methodology, data collection and analysis are discussed to extract findings from data, followed by conclusions and recommendations.

\section{LITERATURE REVIEW}

Since the outbreak of the COVID-19 pandemic, a lot of research has been reported in literature worldwide in general, and the GCC region in particular. This research is mostly collaborative and reports new findings using different aspects of the pandemic. Below, some research works with a focus on engineering education are reported.

The research conducted in [1] reported on the readiness of the UAE in transition to online learning and the preparedness of its institutions in adapting to a new platform to continue learning during this pandemic. The related platforms for online education are discussed along with procedures for their effectiveness, monitoring and regulatory procedures for uninterrupted delivery of educational content through these platforms. The authors claim that these platforms have resulted in a full-fledged effective learning method, and most cases a supplement to traditional teaching. This view requires further research based on all aspects of learning and social challenges. In another study [2], the author aims to understand preferences of online learning due to pandemics and lockdowns since the shift to online learning has generated a large educational experiment. This study was carried out on University of Dubai students. The study shows that $55 \%$ of the surveyed students liked online learning, while $49 \%$ of students favored blended (online and in-class) learning and placed guidelines for the ministry to continue blended learning. This study also revealed the psychological impact on the learning of students.

In work [3], the authors investigate student and faculty satisfaction with institutional readiness and challenges during online learning. Based on this study, the authors note that (i) these challenges include digital divide, communication and interaction between students and instructors, financial issues, and plagiarism (ii) the satisfaction is equal on parts of male or female (iii) faculty appeared more satisfied than students (iv) participants from a college of communication and media seemed more satisfied than other colleges. In another work [4], the authors investigated the impact of demographic characteristics on the academic performance of students. The sample data of grades and grade point averages (GPA) was collected from Al Ain University in Al Ain, the United Arab Emirates and academic performance during pre-COVID and post-COVID learning environments were measured. Statistical analyses such as the Mann-Whitney test, Spearman's rho test, and a regression test were used. The results showed that students performed better during online learning, and it was also found that the number of weaker students dropped sharply by more than $11 \%$ during online learning. The demographic characteristics played a significant role in students' performance and predicted at least a $7.4 \%$ variation in traditional and online learning. Using students' attributes, experiences, and family backgrounds, the study found that online learning should continue side by side with traditional learning.

The authors in [5] addressed questions that include: (i) challenges affecting institutions' abrupt shift to online engineering education during pandemic; (ii) suggest recommendations to address these challenges. The findings identified logistical, technical, and learning/teaching issues and corresponding strategies and intervention mechanisms were suggested. An example related to teaching challenges was a correlation analysis done during this study that showed: (i) instructor's perception of cheating was increased during semi-online asynchronous exams; (ii) instructor's perception of cheating was decreased during fully online or open-book exams. In [6], Vielma and Brey carried out a qualitative survey from several students who participated in asynchronous classes of engineering departments intending to assess the effectiveness of online education during this pandemic. The results show that the students need synchronous instructional content along with asynchronous content to enhance the social element in learning. The study [6] also highlighted the loss of hands-on experience that required physical space with equipment specific tools designed to give experience. The authors [7] aimed to examine the impact on engineering training during the initial phase of the global pandemic. The study carried out a surveybased approach on students from universities of three different countries resulting in three themes: transition, examinations, and perception of the future. The survey targeted questions that addressed software problems used during online lectures, effect on training/internship during the pandemic, issues related to exams, problems related to finishing projects or degree credits, and effect on career plans. In another research [8], the authors present the learning outcomes of student experiences, their feedback, and reflections from instructors due to adaptations and adopted measures for engineering courses during the pandemic. The students' adaptability to the challenges imposed by distance learning has surfaced as the main feature: well-performing students during face-to-face performed well during the distance-learning phase, whereas low-performing students were more affected. The dropout rate in fundamental subjects (22\%) was higher than in technological courses (10\%). To help in assessing the COVID-19 impact on the engineering education community, the American Society for Engineering Education (ASEE) conducted a survey [9] of more than 200 ASEE members. The open-ended responses addressed the initial response to the pandemic, how it progressed through the semester, and what was the outlook for the next term. Another survey as a questionnaire that sought Yes, Maybe/Considering, or No answer was also conducted after ASEE's Annual Conference. The resulting report highlighted themes that included institutional operations, financial and instructional impact, personal productivity and well-being, immediate impact on the workforce, etc. For analysis on engineering education in Gulf Cooperation Council (GCC) region and specialization specific program/course assessments, the reader is referred to [10], [11].

The psychological impact on learning has also been studied during a pandemic [12]. This study aimed to examine the effect of fear of infection, lockdown, and online classes 
on learning, and assess psychological distress. The methods adopted by authors include a cross-sectional study done on participants (on a demographic scale) in the University of Sharjah using a web-based survey. The study conducted on 433 students (64.2\% male, $35.8 \%$ female) showed that $15.9 \%$ of students were anxious, $51 \%$ were with psychological distress and that students with existing mental illness or with older age showed more distress. This study suggested online workshops for online counselling, scheduled activity, and insight guidance. The study [13] aims to understand how the COVID-19 pandemic is affecting mental health and how it differs in different student groups. The specific questions that were addressed include baseline stress levels and related variations per demographic group, and the effect of the pandemic on quality of life like financial security, sleep habits and related variations per demographic group. The findings of this study suggest that mental wellness needs to be understood demographically and that COVID-19 has impacted some underrepresented groups disproportionally.

The research done in [14] investigated the move from face-to-face to blended learning by adding an online group to show the synergy between online and blended approaches in terms of student interaction, satisfaction, dropout rate, and grades. The research showed that adding online resources has a positive effect on learning outcomes. In another research [15], the authors investigate the use of Augmented Reality (AR) technology for training future engineers in the field of energy. This study analyzes the paradigm shift for its usefulness in teaching, for example in power engineering education to support online teaching during the pandemic. In similar research conducted during the pandemic [16], several engineering courses were redesigned for a distance learning environment under some constraints, like core lab courses. Some of the courses developed (for the core part of the curriculum) have gone through a phase-wise approach with significant resource investment from the universities.

Based on the literature review, it is clear that the UAE student community has been affected by factors like fear of infection, social isolation, uncertainty, psychological effects, social divide, switching to online learning, demographics, careers, etc. Only a few research works have examined the global pandemic on its impact on engineering student's mental health. Most of these studies have been conducted with few parameters in mind and excluded computer skills in engineering education. Therefore, there seems to be a need to conduct another study that uses all of these parameters and includes cross-sectional participants for building evidencebased recommendations.

\section{Methodology}

Research problem: After the literature review, one point was clear that the whole picture in terms of impact on engineering students is not addressed by many research works we could find. Each of the research works focused on one or two issues affecting the students' academic performance. Thus, each research work itself alone does not help effectively in the formulation of policies to be set by concerned units in the university to offset challenges posed by the pandemic. This research study aims to investigate most of the parameters/variables for analysis and extract links amongst them to find the net impact on the academic performance of UAE university engineering students.

\section{A. Research Questions}

Based on the discussion above and literature review conducted in this study, the following research questions are proposed, and a hypothesis developed:

Questions:

1. Is there a gender-based difference in engineering students' academic performance through online learning during a pandemic?

2. How do students perceive the challenges during online class and laboratory environments with institutional readiness?

3. What is the level of happiness of UAE university (electrical) engineering students during a pandemic?

Hypotheses:

1. Gender is related to academic performance.

2. Perceived challenges of online learning are positively related to satisfaction with institutional readiness for the online learning environment.

3. Gender moderates the relationship between perceived challenges of online learning and satisfaction with institutional readiness for online learning.

4. Happiness is related to academic performance.

\section{B. Study Population and Study Sample}

As stated in the research problem, the primary objective of this study was to investigate the impact of COVID-19 on the academic performance of UAE university engineering students. The targeted population included engineering participants from perspectives of demography (gender, age, race, and education level). Based on demographic data, the participant represents a stratified random sample, where the population is divided into layers, and then a random sample is selected from each layer or group. As an example of one group or layer, the participant is a representative sample from different regions like UAE national, Arab World, Non-Arab Expat with residence visa, international student with a student visa. The responses received against questions can be used as indicators of academic performance in online learning and relative happiness. There can be three ways to collect this data. Either data about this population can be received through the UAE University Registrar office, or through an open web-based questionnaire or invitations can be sent to this demographic population through email.

\section{Study Instrument}

The data to be collected was decided to be through a questionnaire that addresses research questions stated before. Based on research questions, a questionnaire was developed that represented the objectives of this study. It is shown in Table I. This questionnaire was developed on an open platform like "SurveyMonkey" and was placed online after ethics verification. Responses to survey questions related to the happiness part of the research were decided using the five-point Likert scale as "very satisfied, satisfied, neutral, dissatisfied and very dissatisfied" or "not affected, little affected, neutral, affected, very affected". The challenge questions related to online learning can also be measured as "strongly agreed, agree, neutral, disagree and strongly disagree". These Likert scales were chosen because they are 
the most reliable methods to measure satisfaction, attitudes, perceptions, experiences, and behaviors. The lowest score is 1 and the highest score is 5 . The highest score reflects less satisfaction of the students. The total score of the happiness of the participant can be calculated by adding the total scores for questions and dividing it by several questions. This can be interpreted as the score 1-2 means happy, 2-3 means moderately happy, 3-4 indicates somewhat unhappy, 4-5 refers to rather unhappy or very unhappy. The participants of this study consisted of undergraduate students taking computer courses in electrical engineering. The invitations to participants highlighted that participation in this survey was voluntary and that all the information collected would be kept confidential. The online survey was designed to provide an automatic thank you message to any student, who completed the survey.

TABLE I: QUESTIONNAIRE USED IN THE SURVEY

\begin{tabular}{|c|c|c|}
\hline & Questions & Measuring scale \\
\hline 1 & $\begin{array}{l}\text { Which year of the } \\
\text { University are you currently } \\
\text { in? }\end{array}$ & $2^{\text {nd. }} ; 3^{\text {rd }} ; 4^{\text {th }}$ \\
\hline 2 & What is your gender? & Male; Female \\
\hline 3 & Where are you from? & $\begin{array}{l}\text { UAE National; Arab Expat; Non- } \\
\text { Arab Expat with residence visa; } \\
\text { International student }\end{array}$ \\
\hline 4 & $\begin{array}{l}\text { How has online learning } \\
\text { during pandemics affected } \\
\text { your study habits? }\end{array}$ & $\begin{array}{l}\text { Not affected; Little affected; } \\
\text { Neutral; Affected; Very affected }\end{array}$ \\
\hline 5 & $\begin{array}{l}\text { Has your ability to } \\
\text { concentrate been affected } \\
\text { during online learning? }\end{array}$ & $\begin{array}{l}\text { Not affected; Little affected; } \\
\text { Neutral; Affected; Very affected }\end{array}$ \\
\hline 6 & $\begin{array}{l}\text { Has online learning affected } \\
\text { your ability to establish } \\
\text { rapport with your colleagues } \\
\text { and instructors? }\end{array}$ & $\begin{array}{l}\text { Not affected; Little affected; } \\
\text { Neutral; Affected; Very affected }\end{array}$ \\
\hline 7 & $\begin{array}{l}\text { How has the virtual lab } \\
\text { environment affected your } \\
\text { computer skills for the } \\
\text { degree? }\end{array}$ & $\begin{array}{l}\text { Not affected; Little affected; } \\
\text { Neutral; Affected; Very affected }\end{array}$ \\
\hline 8 & $\begin{array}{l}\text { How has attending virtual } \\
\text { classes affected how you } \\
\text { perceive the program } \\
\text { objectives? }\end{array}$ & $\begin{array}{l}\text { Not affected; Little affected; } \\
\text { Neutral; Affected; Very affected }\end{array}$ \\
\hline 9 & $\begin{array}{l}\text { How has the virtual } \\
\text { environment during the } \\
\text { pandemic affected your } \\
\text { career outlook? }\end{array}$ & $\begin{array}{l}\text { Not affected; Little affected; } \\
\text { Neutral; Affected; Very affected }\end{array}$ \\
\hline 10 & $\begin{array}{l}\text { How has your motivation } \\
\text { for your studies been } \\
\text { affected by the pandemic? }\end{array}$ & $\begin{array}{l}\text { Not affected; Little affected; } \\
\text { Neutral; Affected; Very affected }\end{array}$ \\
\hline
\end{tabular}

\section{DATA COLLECTION AND ANALYSIS}

The invitation to participate in the study was sent as a web link to selected students chosen randomly from each demographic group. The participants were required to indicate their agreement/satisfaction or disagreement/dissatisfaction against each question by choosing a number for each corresponding scale. To ensure the validity of this study, this study was thought of at least 20-30 participants of spring term computer courses (namely programming ELEC230, microprocessors ELEC451; computer organization ELEC462) of electrical engineering to complete this survey and then analyze its results before placing the questionnaire to a larger section of participants. Finally, this survey was sent to 90 selected students of both courses, who were registered in the courses. Of these 90 participants, 79 responded and completed the survey. As this response data is quantitative, hence Statistical Package for the Social Sciences (SPSS) was picked for analysis as it is an interactive tool. The collected data represents $55.8 \%$ from year $4,25.63 \%$ from year 3 , and the remaining $18.57 \%$ from year 2 . Of these total 79 participants, $45.28 \%$ were male, and the remaining $54.72 \%$ were females; and geographically distributed as $70.77 \%$ UAE nationals, $14.14 \%$ Arab ex-pats, and $15.09 \%$ non-Arab ex-pats. The responses to questions from 1-3 were used to create demographical representations of data. The responses to questions (from 4-10) were used to correspond to the impact on happiness and challenges to academic performance. These are illustrated in Fig. 1.

The happiness score can also be measured by accumulating these responses against research questions and divided by the number of questions. The data analysis against each research question is shown in tabular format in Table 2. The resulting data shows that females were more affected than males (refer to research question 1); the challenges posed by the pandemic have affected students' study habits, concentration, motivation and rapport with instructors and colleagues (refer to research question 2); and that student's mental health and social life has been affected during pandemic (refer research question 3). As per discussion in the previous section, the (lowest to highest) individual scores were also added up for all seven questions and divided by seven gave us the same percentage score.

TABLE II: RESEARCH QUESTIONS AND ANALYSIS

\begin{tabular}{|c|c|c|}
\hline & Research Question & Questions 4-10 \\
\hline 1 & $\begin{array}{l}\text { Is there a gender-based } \\
\text { difference in students' } \\
\text { academic performance } \\
\text { using online learning } \\
\text { during a pandemic? }\end{array}$ & $\begin{array}{l}\text { Affected/Very affected: Q4 (25 males } \\
\text { and } 32 \text { females); Q5 ( } 22 \text { males, } 33 \\
\text { females); Q6 ( } 21 \text { males, } 30 \text { females); Q7 } \\
\text { ( } 22 \text { males, } 25 \text { females); Q8 ( } 23 \text { males, } 24 \\
\text { females); Q9 ( } 23 \text { males, } 24 \text { females); } \\
\text { Q10 ( } 29 \text { males, } 34 \text { females) } \\
\text { Comment: Females are more affected } \\
\text { than males. }\end{array}$ \\
\hline 2 & $\begin{array}{l}\text { How do students } \\
\text { perceive the challenges } \\
\text { during online class and }\end{array}$ & $\begin{array}{l}\text { Affected/Very affected: Q4 }(72.41 \%) \text {; } \\
\text { Q5 }(69.67 \%) \text {; Q6 }(65.51 \%) \text {; Q7 }(60 \%) \text {; } \\
\text { Q8 }(58.62 \%)\end{array}$ \\
\hline & $\begin{array}{l}\text { laboratory } \\
\text { environments with } \\
\text { institutional readiness? }\end{array}$ & $\begin{array}{l}\text { Comment: Students find online } \\
\text { learning affecting their studies. }\end{array}$ \\
\hline 3 & $\begin{array}{l}\text { What is the level of } \\
\text { happiness of UAE } \\
\text { students during the } \\
\text { pandemic? }\end{array}$ & $\begin{array}{l}\text { Affected/Very affected: Q9 }(58.62 \%) \text {; } \\
\text { Q10 }(79.31 \%) \\
\text { Comment: Students in computer } \\
\text { classes are not happy during the } \\
\text { pandemic. }\end{array}$ \\
\hline
\end{tabular}

\section{CONCLUSIONS AND RECOMMENDATIONS}

The sudden appearance of COVID-19 caught all of us by surprise. Though UAE government in general, and UAE University in particular put all resources together and brought all of us to online learning to reduce the impact of the pandemic. Soon, the pandemic brought levels of satisfaction, happiness, and feelings down. The objectives in this study were set to answer few research questions that were developed during the study of current literature that addressed the impact of COVID-19 on student's academic performance from many aspects. The gender, demography and study year of the student were chosen in selecting the population of participants to answer a questionnaire-based survey that sought participant response based on gender, challenges posed by pandemic and linking happiness to academic performance. Total 79 participants out of 90 
responded to this request. Data collected were analyzed using SPSS software, which showed results as expected, as stated in the hypothesis stated in this study. To strengthen the findings of this study and make them more reliable, a larger number of UAE university engineering students or more preferably can be selected to accumulate data for analysis. This data collection will direct us to come up with a solid and fruitful recommendation for concerned persons in UAE University in particular in curbing the impact of COVID-19 on engineering student's academic performance.

Based on data collected in this study, the electrical engineering students seem to be unhappy and very concerned about their future outlook in terms of job availability, lack of computer-related skills needed for job placement, etc. Since this pandemic has affected the economics of each country, the related engineering industries have already started moving to industry 4.0 technologies to cut their costs. This, in contrast, has further complicated the positive learning to create engineers (from a virtual lab environment) fit for industry 4.0 companies.

To uplift students' academic performance during the pandemic, the engineering instructors are required to abreast themselves of students' needs and concerns associated with academic emotions to satisfy positive learning experiences in engineering education. One way could be to create virtual groups from amongst students in parallel to online classes to get students involved in learning. More research needs to be conducted in this direction.

Regarding engineering accreditation, more effort is required to be exercised to ensure that online instruction of engineering courses satisfies Accreditation Board for Engineering and Technology (ABET) requirements. In other words, the online assessment process still raises functional, technical, and ontological concerns that need to be addressed.

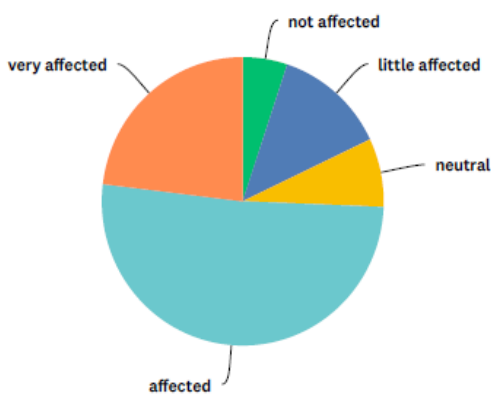

Question 4

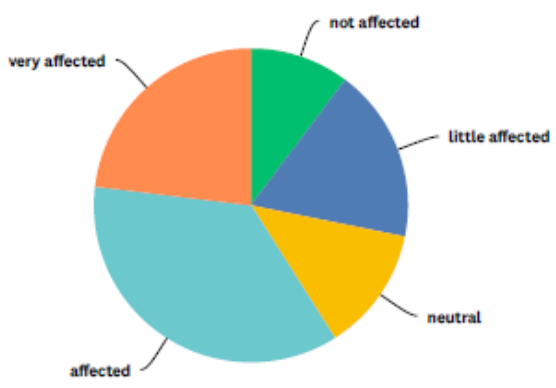

Question 7

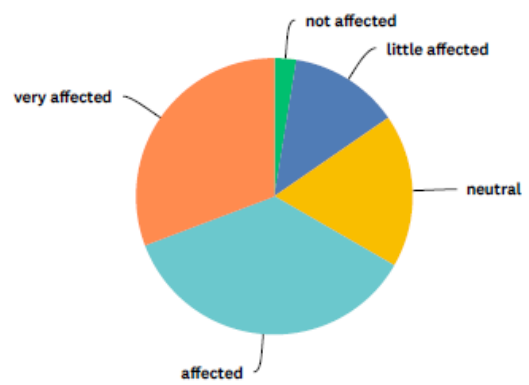

Question 5

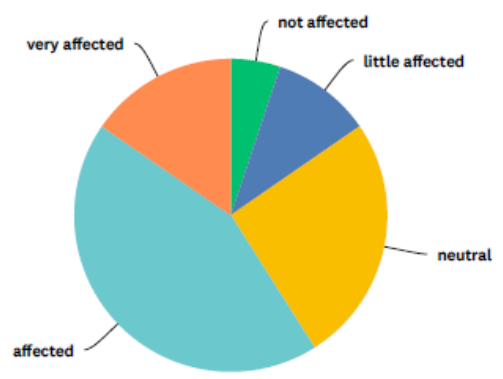

Question 8

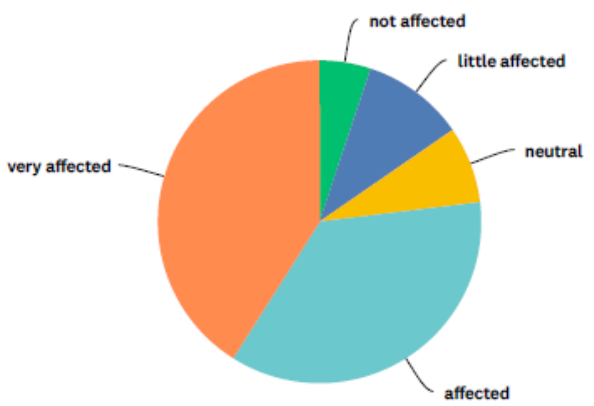

Question 10

Fig.1. Survey results are shown as a pie chart.

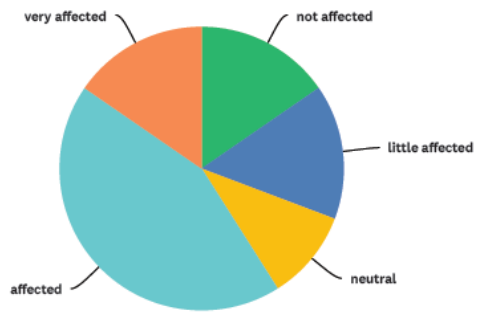

Question 6

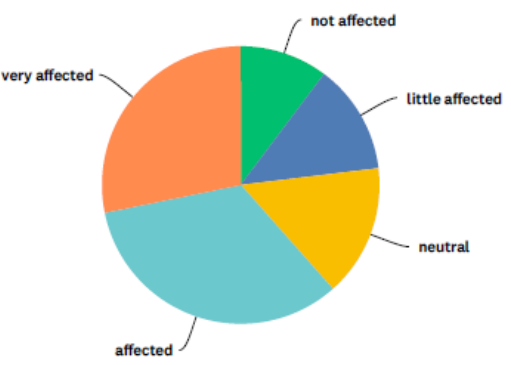

Question 9 


\section{REFERENCES}

[1] D. Alterri, M. Hindi, R. AlMarar, R. Shubair, "Transition to distance learning during the COVID-19 pandemic: Efforts within the Higher Education sector in the United Arab Emirates," Journal of Applied Learning, and Teaching, vol. 3, no. 2, October 2020, doi: 10.37074/jalt.2020.3.2.17.

[2] N. Almuraqab., "Shall Universities at the UAE Continue Distance Learning after the COVID-19 Pandemic? Revealing Students' Perspective," International Journal of Advanced Research in Engineering and Technology, vol. 11, no. 5, pp. 226-233, May 2020.

[3] G. El Refae, A. Kaba, S. Eletter, "Distance learning during COVID-19 pandemic: satisfaction, opportunities and challenges as perceived by faculty members and students", Interactive Technology and Smart Education, 2021, https://doi.org/10.1108/ITSE-08-2020-0128.

[4] G. El Refae, A. Kaba, S. Eletter., "The Impact of Demographic Characteristics on Academic Performance: Face-to-Face Learning Versus Distance Learning Implemented to Prevent the Spread of COVID-19," The International Review of Research in Open and Distributed Learning, vol. 22, no. 1, pp. 91-110, 2021, https://doi.org/10.19173/irrodl.v22i1.5031.

[5] S. Asgari, J. Trajkovic, M. Rahmani, W. Zhang, C. Lo, A. Sciortino, "An observational study of engineering online education during the COVID-19 pandemic," PLOS ONE, vol. 16, no. 4: e0250041. https://doi.org/10.1371/journal.pone.0250041, 2021.

[6] K. Vielma, B. Brey, "Using Evaluative Data to Assess Virtual Learning Experiences for Students During COVID-19," Biomedical Engineering Education, vol. 1, no. 1, January 2021, 2020, pp. 139-144, https://doi.org/10.1007/s43683-020-00027-8.

[7] P. Åhag, Y. J. Hsu, L. Olsson and L. Sundberg, "The Impact of SARSCoV-2 on Engineering Education: Student Perceptions from Three Countries," IEEE International Conference on Industrial Engineering and Engineering Management, 2020, pp. 1266-1270, doi: 10.1109/IEEM45057.2020.9309900.

[8] M. García-Alberti, F. Suárez, I. Chiyón, F. Mosquera, "Challenges and Experiences of Online Evaluation in Courses of Civil Engineering during the Lockdown Learning Due to the COVID-19 Pandemic. Educ. Sci. 2021, 11, 59. https://doi.org/10.3390/educsci11020059.

[9] American Society for Engineering Education, COVID-19 \& Engineering Education: An interim report on the community response to the pandemic and racial justice, 2020, Washington, DC.

[10] Q. Memon, "On analysis of electrical engineering programme in GCC countries," European Journal of Engineering Education, vol. 32, no. 5, pp. 551-560, 2007.

[11] Q. Memon, A. Harb, S. Khoja, "Specialization-Specific Course Assessments Integrated for Program Assessment," Education Research International, vol. 2012, Article ID 987543, 10 pages, 2012, https://doi.org/10.1155/2012/987543.

[12] C. Saravanan, I. Mahmoud, W. Elshami, M. Taha, "Knowledge, Anxiety, Fear, and Psychological Distress About COVID-19 Among University Students in the United Arab Emirates," Front. Psychiatry 11:582189, 2020, doi: 10.3389/fpsyt.2020.582189.

[13] A. Danowitz, K. Beddoes, "Effects of COVID-19 on Engineering Students' Baseline Stress," Proceedings of the AAEE2020 Conference, Sydney, Australia, December 2020.

[14] P. J. Martínez, F. J. Aguilar and M. Ortiz, "Transitioning from Face-toFace to Blended and Full Online Learning Engineering Master's Program," IEEE Transactions on Education, vol. 63, no. 1, pp. 2-9, Feb. 2020, doi: 10.1109/TE.2019.2925320.

[15] I. Opriș, C. Ionescu, S., Costinaș, D. Nistoran, "Challenges and Opportunities to Overcome the Impact Of COVID-19 Pandemic on Power Engineering Education," TEM Journal, vol. 9, issue 4, pp. 16871691, ISSN 2217-8309, doi: 10.18421/TEM94-48, November 2020.

[16] J. Park, M. Park, K. Jackson, G. Vanhoy, "Remote Engineering Education Under COVID-19 Pandemic Environment," International Journal of Multidisciplinary Perspectives in Higher Education, vol. 5, issue 1, pp. 160-166, 2020.

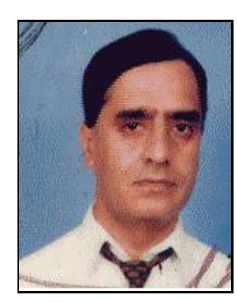

Qurban A. Memon received an MS degree in electrical engineering from the University of Gainesville, Florida in 1993 and earned a PhD degree in electrical engineering from the University of Central Florida, the US in 1996.

His work experience spans over 24 years, all in academia. For the last sixteen years, he is serving UAE university in the electrical engineering department of the college of engineering, UAE university, where he is currently an associate professor. He has authored/co-authored over hundred publications in his academic career. He has executed research grants and development projects in the area of intelligent based systems, security and networks. $\mathrm{He}$ has served as a reviewer of many international journals and conferences as well as session chair at various conferences.

Professor Memon has edited two books published by CRC Press and won the Chancellors research award in 2009 and 2017. 